\title{
Neonatal iodine exposure
}

INSERM

\section{Source}

INSERM. (1999). Orphanet: an online rare disease and orphan drug data base. Neonatal iodine exposure. ORPHA:238688

Neonatal iodine exposure is a rare endocrine disease characterized by the appearance of transient hypothyroidism, usually in preterm newborns, following long or short-term topical iodine exposure. Parenteral exposure from iodinated contrast agents may similarly alter thyroid funtion in term neonates. 